\title{
COMPRIMENTO CRÍTICO DE DECLIVE RELACIONADO À EROSÃO HÍDRICA, EM TRÊS TIPOS E DOSES DE RESÍDUOS EM DUAS DIREÇÕES DE SEMEADURA DIRETA ${ }^{(1)}$
}

\author{
Fabrício Tondello Barbosa ${ }^{(2)}$, Ildegardis Bertol ${ }^{(3)}$, Romeu de Souza Werner ${ }^{(4)}$, Júlio \\ César Ramos ${ }^{(4)}$ \& Roger Robert Ramos ${ }^{(4)}$
}

\begin{abstract}
RESUMO
Nos preparos conservacionistas de solo, a eficácia dos resíduos culturais na redução da erosão hídrica diminui se os resíduos forem transportados pela enxurrada e, ou, se esta sulcar o solo. A esse fenômeno denomina-se falha dos resíduos, caracterizando a existência de comprimento crítico de declive, ou seja, estabelece a distância no terreno a partir da qual a enxurrada adquire tensão cisalhante suficiente para superar a resistência do resíduo ao transporte e, ou, a resistência do solo ao sulcamento. $O$ objetivo deste trabalho foi averiguar a existência de comprimentos críticos de declive em duas direções de semeadura direta, sob diferentes tipos e doses de resíduos culturais. $O$ trabalho foi desenvolvido em campo, entre maio de 2009 e maio de 2011, sobre um Nitossolo Bruno aluminoférrico húmico, em São José do Cerrito (SC), usando unidades experimentais com dimensões de 3,5 x $11 \mathrm{~m}$, com declividade média de $0,144 \mathrm{~m} \mathrm{~m}^{-1}$. Foram testadas as formas de execução de semeadura no sentido transversal (em contorno) e paralelo ao declive (na pendente), sobre os resíduos culturais de milho (Zea mays), trigo (Triticum aestivum) e soja (Glycine max), nas doses de 50 e $100 \%$ dos resíduos produzidos. Foram realizados testes de chuva simulada, com o uso de simulador de chuva de braços rotativos, na intensidade de chuva planejada de $65 \mathrm{~mm} \mathrm{~h}^{-1}$ e com duração de 90 min cada um - tempo esse necessário para se obter a taxa constante de enxurrada. Ao final dos $90 \mathrm{~min}$ de chuva, sem desligar o aparelho simulador de chuva, foram aplicados níveis crescentes de fluxo extra de água limpa na cabeceira das parcelas, simulando a enxurrada provinda de declives mais longos. Para identificação da falha dos resíduos,
\end{abstract}

\footnotetext{
(1) Parte da Tese de Doutorado do primeiro autor. Recebido para publicação em 20 de setembro de 2011 e aprovado em 10 de maio de 2012.

${ }^{(2)}$ Professor do Departamento de Solos e Recursos Naturais, Centro de Ciências Agroveterinárias - CAV, Universidade do Estado de Santa Catarina - UDESC. CEP 88520-000 Lages (SC). E-mail: fabriciotondello@gmail.com

(3) Professor do Departamento de Solos e Recursos Naturais, CAV/UDESC. E-mail: a2ib@cav.udesc.br

${ }^{(4)}$ Mestrandos em Ciência do Solo, CAV/UDESC. E-mail: tiomone@msn.com; julio.ramos.ta@gmail.com; ramosrogerrobert@hotmail.com
} 
utilizou-se a teoria de erosão, efetuando as relações entre taxa de erosão ( $\left.D_{p}\right)$ x taxa de enxurrada $\left(q_{m}\right)$ e concentração de sedimentos na enxurrada (C) $x$ taxa de enxurrada $\left(q_{m}\right)$. Detectou-se comprimento crítico de declive em todos os tratamentos; de modo geral, a semeadura direta em contorno e a dose maior dos resíduos de milho, trigo e soja aumentaram o comprimento crítico de declive em relação à semeadura direta na direção da pendente e à menor dose de resíduos, respectivamente. Esses comprimentos variaram de 35 a $155 \mathrm{~m}$. Da teoria de erosão, o ponto de falha foi mais bem identificado analisando conjuntamente as relações $D_{p} \times q_{m}$ e $\times q_{m}$.

Termos de indexação: chuva simulada, falha dos resíduos culturais, preparos conservacionistas de solo, cultivo em contorno.

\title{
RESUMO: CRITICAL SLOPE LENGTH FOR WATER EROSION FOR THREE CROP RESIDUE TYPES AND RATES IN TWO SOWING DIRECTIONS IN NO-TILL
}

\begin{abstract}
Under conservation tillage systems, the effectiveness of crop residues in reducing water erosion decreases if the mulch is carried away by runoff and / or if the runoff furrows the soil. This phenomenon is called mulch failure, characterizing the critical slope length, i.e., the distance on the ground after which the runoff shear stress is sufficient to overcome the resistance of the mulch to be carried away and / or the resistance of the soil to furrowing. The objective of this study was to define critical slope lengths in two sowing directions under different types and doses of crop residues, under no-tillage. The field work was conducted from May 2009 to May 2011, on a Nitosol (Alfisol) in São José do Cerrito, Santa Catarina, Brazil, in experimental units $(3.5 \times 11 \mathrm{~m})$ with a mean slope of $0.144 \mathrm{~m} \mathrm{~m}^{-1}$. Transverse (contour) and parallel sowing directions (up-and-down) to the slope were tested using maize (Zea mays), wheat (Triticum aestivum) and soybean (Glycine max) mulches at doses of 50 and 100\% of the total residue produced. During the research, rainfall was simulated using a rotating-boom rainfall simulator, with a rain intensity of $65 \mathrm{~mm} \mathrm{~h}^{-1}$ in $90 \mathrm{~min}$, which was the time required until the runoff rate became constant. At the end of 90 min of rain, without disconnecting the rainfall simulator, increasing levels of extra flow of clean water were applied at the upper part of the plots, simulating additional runoff from longer slopes. The mulch failure was evaluated based on the theory of erosion, using the relationship between erosion rate $\left(D_{p}\right) x$ runoff rate $\left(q_{m}\right)$ and sediment concentration in runoff $(C) x$ runoff rate $\left(q_{m}\right)$. In all treatments the critical slope lengths were determined, and, in general, contour sowing and higher amounts of crop residues increased the critical slope length in relation to the up-and-down sowing and the lowest residue dose, respectively. These critical lengths ranged from 35 to $155 \mathrm{~m}$. The point of failure of the theory of erosion was best identified by a combined analysis of the relationships $D_{p} \times q_{m}$ and $C \times q_{m}$.

Index terms: Simulated rainfall, mulch failure, conservation soil tillage, contour farming.
\end{abstract}

\section{INTRODUÇÃO}

Na semeadura direta, a ausência de preparo prévio do solo preserva a quase totalidade dos resíduos culturais em sua superfície, reduzindo a erosão hídrica em relação ao manejo do solo com preparo prévio realizado com arado e grade (Schick et al., 2000; Cogo et al., 2003). Esse procedimento contribuiu para disseminar a ideia entre agricultores e técnicos de campo da região Sul do Brasil de que a semeadura direta, por si só, controla eficazmente a erosão hídrica, o que resultou no abandono do cultivo em contorno $\mathrm{e}$ dos terraços agrícolas, induzindo a realização das operações de manejo do solo na direção da pendente do terreno (Dernardin et al., 2005; Barbosa, 2011).
Embora a semeadura direta reduza a erosão, as perdas de água são menos alteradas do que as perdas de solo, pois este possui limite de infiltração de água. Ultrapassado o limite, a água escoa sobre o terreno independentemente do tipo de manejo adotado (Kohnke, 1968). Por esse motivo, a ocorrência de chuvas críticas, em longos comprimentos de rampa e declives acentuados, potencializa a enxurrada, e a tensão cisalhante adquire energia suficiente para remover o resíduo ou, mesmo sem removê-lo, promover o aumento na erosão em sulcos. A esse fenômeno denomina-se falha do resíduo, o que caracteriza o comprimento crítico de declive, definido pela distância no terreno a partir da qual ocorre redução da eficácia do resíduo em controlar a erosão 
(Wischmeier, 1973; Foster et al., 1982a, b). Com a falha, os valores para o fator C (cobertura e manejo do solo) utilizados na equação de predição de perda de solo USLE (Wischmeier \& Smith, 1978) e RUSLE (Renard et al., 1997) não são mais válidos a partir do comprimento crítico de declive, devido ao aumento do fator C (Wischmeier, 1973). Esses modelos são ainda alterados pelo aumento do valor do expoente do fator L (comprimento do declive) dessa equação, devido ao aumento da erosão em sulcos em função da falha do resíduo (Foster et al., 1982a). Estudos com comprimentos críticos de declive podem ser utilizados para auxiliar na definição do espaçamento entre terraços em semeadura direta (Bertol \& Cogo, 1996; Bertol et al., 2000) e, por isso, têm alta importância prática e científica.

O ponto no terreno onde ocorre a falha do resíduo pode ser verificado por meio de observação visual em campo e por análise de relações baseadas em teoria de erosão (Foster et al., 1982a). A falha visual em campo pode ocorrer por três formas: remoção peça por peça, que geralmente ocorre em baixas quantidades de resíduo; remoção em massa, quando a quantidade de resíduo é elevada; e o fluxo escoa e erode o solo por baixo do resíduo, sem removê-lo. No entanto, o comprimento crítico detectado pela falha visual é subjetivo e, para maior segurança, devem ser examinadas as relações teóricas de erosão. Da teoria de erosão, Foster et al. (1982a) analisaram três relações:i) taxa de erosão $\left(D_{p}\right) \times$ taxa de descarga $\left(q_{m}\right)$, sendo que a $\mathrm{D}_{\mathrm{p}}$ em uma parcela varia linearmente com $q_{m}$ conforme a equação $D_{p}=\left(K_{s} C_{s} q_{m}\right)+C_{2}$, em que $\mathrm{K}_{\mathrm{s}}$ é o coeficiente de erodibilidade em sulcos, $\mathrm{C}_{\mathrm{s}}$ é o fator cobertura e manejo do solo em sulcos, $\mathrm{q}_{\mathrm{m}}$ é a taxa de descarga no centro da parcela e $\mathrm{C}_{2}$ é um coeficiente que depende da erosão entre sulcos. Com isso, $\mathrm{C}_{2}$ é o coeficiente linear, e o termo $\mathrm{K}_{\mathrm{s}} \mathrm{C}_{\mathrm{s}}$, o coeficiente angular da reta da relação $\mathrm{D}_{\mathrm{p}} \times \mathrm{q}_{\mathrm{m}}$. Dessa forma, a declividade da reta é expressa por $\Delta D_{p} / \Delta q_{m}$ $=\mathrm{K}_{\mathrm{s}} \mathrm{C}_{\mathrm{s}}$. Quando ocorre a falha, o fator $\mathrm{C}_{\mathrm{s}}$ aumenta, aumentando a declividade da reta da relação $D_{p} \times q_{m}$; ii) concentração de sedimentos na enxurrada $(\mathrm{C}) \mathrm{x}$ taxa de descarga $\left(\mathrm{q}_{\mathrm{m}}\right)$. Até o momento de ocorrência da falha do resíduo, a concentração de sedimentos na enxurrada decresce com o aumento da taxa de descarga, conforme a equação $\mathrm{C}=\mathrm{K}_{\mathrm{s}} \mathrm{C}_{\mathrm{s}}+\mathrm{C}_{2} / \mathrm{q}_{\mathrm{m}}$. $\mathrm{O}$ valor de $\mathrm{C}_{\mathrm{s}}$ aumenta no momento de ocorrência da falha e, com isso, aumenta também o valor de $C$; e iii) velocidade da enxurrada $(\mathrm{V}) \mathrm{x}$ taxa de descarga $\left(\mathrm{q}_{\mathrm{m}}\right)$. No momento da falha, ocorre mudança na curva da relação entre $\mathrm{V}$ $\mathrm{x}_{\mathrm{m}}$, pela alteração na rugosidade hidráulica e, ou, no grau de sulcamento da superfície do solo.

Em trabalhos realizados por outros autores sob preparos conservacionistas, Laflen et al. (1978) não observaram falha dos resíduos para comprimentos de até $50 \mathrm{~m}$. Cogo (1981) não observou falha de resíduos de trigo ancorados em semeadura direta para comprimentos de até $135 \mathrm{~m}$. Foster et al. (1982a) observaram falhas variando de 45 a $200 \mathrm{~m}$ e de 40 a $150 \mathrm{~m}$ em solos não suscetíveis e suscetíveis ao sulcamento, respectivamente, sob colmos de milho e resíduo de trigo, não ancorados na superfície do solo. Bertol (1995) encontrou limites de comprimento crítico de declive para semeadura direta variando de 328 a $483 \mathrm{~m}$, de 157 a $272 \mathrm{~m}$, de 106 a $143 \mathrm{~m}$ e de 87 a 174 , sobre resíduo de milho, trigo + milho, trigo recémcolhido e trigo + milho, 140 dias após a colheita do trigo em superfície semeada, respectivamente, em um Argissolo Vermelho-Amarelo de textura francoargiloarenosa com declividade de 6,6\%. Morais (1999), no mesmo solo sob semeadura direta, observou falha variando nos limites de 20 a $109 \mathrm{~m}$, de 99 a $110 \mathrm{~m}$ e de 107 a $164 \mathrm{~m}$, sobre resíduo de soja, aveia-preta e milho, respectivamente, tendo o comprimento crítico variado com o tipo, a quantidade e a forma de manejo dos resíduos. $\mathrm{O}$ referido autor também concluiu que a relação $D_{p} \times q_{m}$ foi o melhor indicador teórico da falha. Amaral (2010), testando o uso ou não de hastes sulcadoras acopladas à semeadora sobre resíduo de milho em semeadura direta, em um Nitossolo, constatou a falha do resíduo pela observação visual em campo, e em apenas um dos tratamentos constatou-se a falha por teoria de erosão. A remoção de resíduos ocorreu nos intervalos de 171 a $456 \mathrm{~m}$ e de 64 a $118 \mathrm{~m}$, com e sem as hastes sulcadoras, respectivamente.

O objetivo deste trabalho foi averiguar, por análise de relações baseadas em teoria de erosão, a existência de comprimentos críticos de declive no sistema de semeadura direta, em que a operação de semeadura foi realizada nas direções paralela (na pendente) e transversal (em contorno) ao declive, usando os resíduos vegetais de milho, trigo e soja nas quantidades de 50 e $100 \%$ do total produzido, para cada um deles.

\section{MATERIAL E MÉTODOS}

O experimento sob condições de chuva simulada foi conduzido em campo entre maio de 2009 e maio de 2011, em São José do Cerrito (SC), Brasil, com coordenadas no ponto central da área experimental de $27^{\circ} 43^{\prime} \mathrm{S}$ e $50^{\circ} 31^{\prime} \mathrm{W}$ e altitude de $800 \mathrm{~m}$. O clima é do tipo Cfb (Köppen), e o solo, um Nitossolo Bruno aluminoférrico húmico, muito argiloso (Embrapa, 2006), cuja camada superficial de $0-0,05 \mathrm{~m}$ tem $62 \%$ de argila, $10 \%$ de silte e $28 \%$ de areia, com teor de carbono orgânico de $25 \mathrm{~g} \mathrm{~kg}^{-1}$ e densidade do solo de $1,38 \mathrm{~g} \mathrm{~cm}^{-3}$. Nos últimos seis anos, antes do experimento, a área foi cultivada sob semeadura direta e, antes disso, sob preparo convencional do solo. As parcelas tinham $3,5 \times 11 \mathrm{~m}$, conforme recomendações do Iapar (1975), delimitadas nas laterais e extremidades superiores por chapas galvanizadas e, nas extremidades inferiores, por calhas coletoras de enxurrada, as quais estavam conectadas a uma tubulação de PVC que permitia a condução do fluxo até uma câmara com vertedor medidor de vazão de cada parcela.

Os tratamentos foram formados pela combinação de duas direções de semeadura, duas doses e três tipos 
de resíduo cultural. O experimento foi realizado em três épocas diferentes; em cada uma, foi avaliado um tipo específico de resíduo cultural. Na primeira época (junho de 2010), correspondente ao primeiro teste de chuva simulada, foi utilizado o resíduo de milho; na segunda época (dezembro de 2010), correspondente ao segundo teste, o resíduo de trigo; e, na terceira época (maio de 2011), correspondente ao terceiro teste, o resíduo de soja. Para cada tipo de resíduo, foram testadas duas direções de semeadura direta, no sentido transversal (em contorno) e paralelo ao declive (na pendente), e duas doses de resíduo cultural, equivalentes a 50 e $100 \%$ do total produzido. A distribuição seguiu o delineamento inteiramente casualizado, em duas repetições, sendo as direções de semeadura e as doses de resíduo combinadas em esquema fatorial, totalizando oito parcelas. Cada parcela recebeu a mesma direção de semeadura e dose de resíduo nas três épocas. Imediatamente antes de cada teste de chuva, realizou-se operação de semeadura mecanizada, sem uso de sementes e adubos, com o propósito de criar marcas de preparo nas direções em contorno e na pendente, conforme o tratamento. Sobre os resíduos do milho e da soja, utilizou-se semeadora para culturas de inverno, dotada de discos de corte regulados para a profundidade de $0,04 \mathrm{~m}$ e espaçamento entre linhas de $0,2 \mathrm{~m}$. Sobre o resíduo de trigo, a semeadora era para culturas de verão, dotada de discos de corte e hastes sulcadoras, reguladas para profundidade de $0,08 \mathrm{~m}$ e espaçamento entre linhas de $0,5 \mathrm{~m}$. No quadro 1 encontram-se a massa de resíduo cultural produzido e a percentagem de cobertura do solo antes e após a operação de semeadura nos tratamentos estudados. A cobertura do solo foi determinada por meio do método da corda marcada, descrito por Sloneker \& Moldenhauer (1977).

Para a realização dos testes de chuva, utilizou-se um simulador de chuva de braços rotativos (Swanson, 1965), o qual cobria simultaneamente duas unidades experimentais. Para cada teste, correspondente a um tipo de resíduo cultural, aplicou-se uma chuva por par de parcelas com intensidade de $65 \mathrm{~mm} \mathrm{~h}^{-1} \mathrm{e}$ duração de 90 min, denominada de chuva inicial, que tinha o propósito de obter a taxa constante de enxurrada para, com isso, ser possível simular por meio da adição de fluxos extras de água na cabeceira das parcelas comprimentos de declive maiores que $o$ segmento de $11 \mathrm{~m}$ destas. Durante a chuva inicial, mediu-se com proveta a taxa de enxurrada em intervalos de $5 \mathrm{~min}$, até o final dos $90 \mathrm{~min}$. Imediatamente após os $90 \mathrm{~min}$ de chuva, sem interrupção e mantendo-se o simulador de chuva funcionando com a mesma intensidade de precipitação, foram adicionados de forma crescente fluxos extras de água limpa (isenta de sedimentos) na extremidade superior das parcelas, com duração de 9 min cada nível, a fim de simular comprimentos progressivamente mais longos que o da parcela, seguindo método de Swanson \& Dedrick (1966). Para o experimento 1 , foram aplicados seis níveis de fluxo extra: 0,$3 ; 0,6 ; 0,9 ; 1,2 ; 1,5 ;$ e $3,0 \mathrm{~m}^{3} \mathrm{~s}^{-1} \mathrm{~m}^{-1} \times 10^{-3}$ (lêse: metro cúbico por segundo por metro de largura da

Quadro 1. Massa seca de resíduos na superfície do solo antes da semeadura e cobertura do solo antes e após a semeadura que antecedeu cada teste de chuva simulada com adição de fluxos extras de água, sobre duas doses de resíduos culturais de milho, trigo e soja em duas direções de semeadura direta

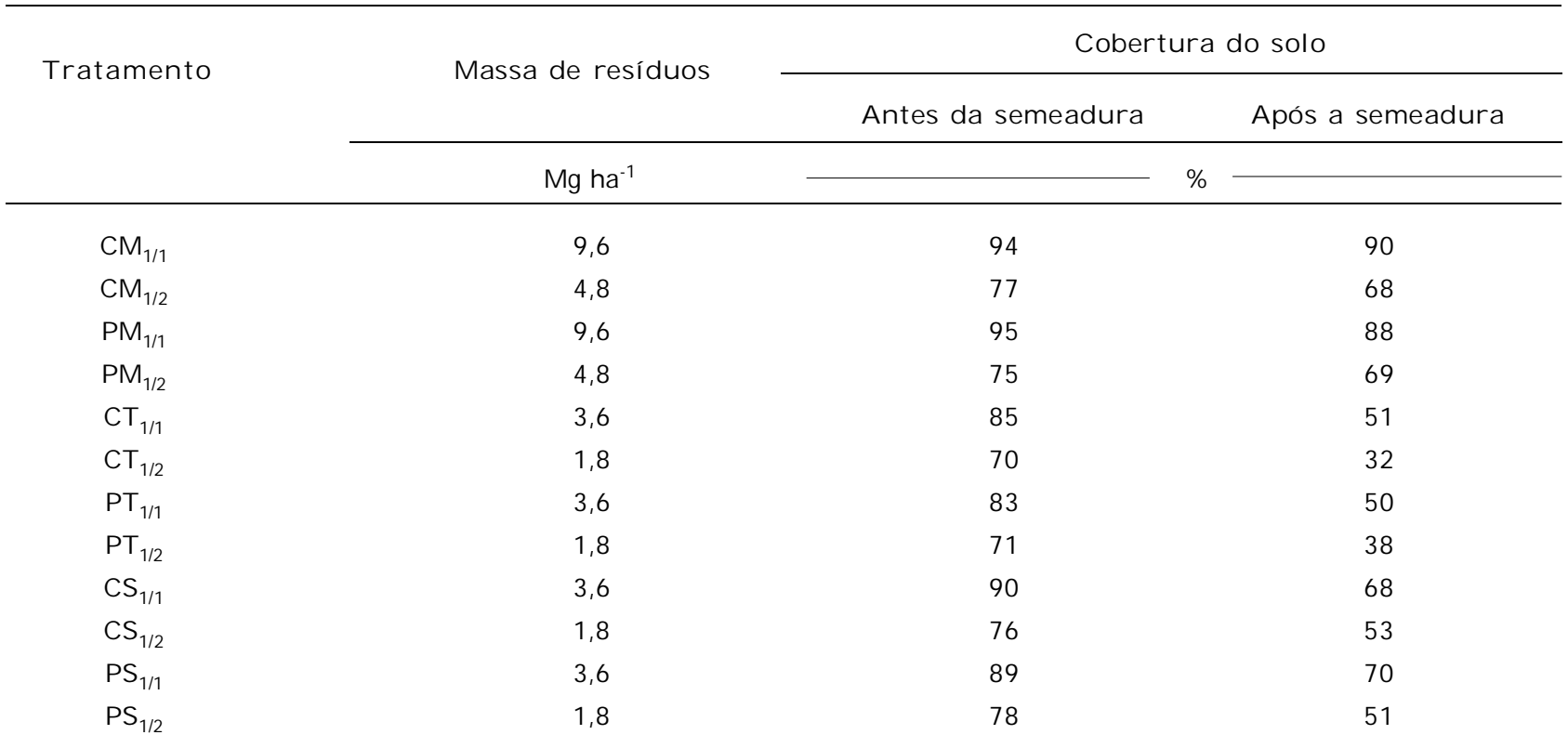

C: semeadura em contorno ao declive; P:semeadura no sentido da pendente; M:resíduo de milho; T:resíduo de trigo; S:resíduo de soja; ${ }_{1 / 1}$-dose de resíduo de $100 \%$ do total produzido; ${ }_{1 / 2}$-dose de resíduo de $50 \%$ do total produzido. (Média das repetições) 
parcela), enquanto, para os experimentos 2 e 3 , foram adicionados sete níveis de fluxo: 0,$3 ; 0,6 ; 0,9 ; 1,2 ; 1,5$; 2,$2 ;$ e $3,0 \mathrm{~m}^{3} \mathrm{~s}^{-1} \mathrm{~m}^{-1} \times 10^{-3}$. A separação dos níveis de fluxo fez-se da seguinte maneira: após os $90 \mathrm{~min}$ de chuva, sem interromper o funcionamento do simulador, iniciou-se a adição do primeiro nível de fluxo extra de água. Nesse momento, a medição da enxurrada passou a ser efetuada em um vertedor (triangular tipo Thompson com ângulo de abertura de $90^{\circ}$ ) acoplado à calha coletora de enxurrada. Com base na taxa constante de enxurrada da chuva anterior ao fluxo extra, sabia-se previamente qual deveria ser a altura da lâmina de enxurrada no vertedor para cada nível de fluxo. Com isso, um registro acoplado à tubulação (que conduzia a água até a parcela) era aberto até a enxurrada atingir a altura desejada no vertedor. Cada nível de fluxo tinha duração de 9 min, sendo as leituras de vazão realizadas aos 3 , 6 e $9 \mathrm{~min}$. Ao final da terceira leitura, regulava-se novamente o registro para atingir o nível seguinte de fluxo. A taxa de enxurrada em cada nível foi calculada por uma média das três leituras. Durante as leituras, coletaram-se amostras da enxurrada em potes, para determinação da sua concentração de sedimentos.

A taxa de erosão $\left(\mathrm{D}_{\mathrm{p}}\right)$ foi calculada multiplicandose a concentração de sedimentos (C) pela taxa de enxurrada. A taxa de descarga no ponto médio da parcela $\left(q_{m}\right)$ foi obtida conforme Foster et al. (1982a), pela equação $q_{m}=\left(q_{i}+q_{a}\right) / 2$, em que $q_{i}$ é a taxa de descarga no final da parcela (medido no vertedor) e $q_{a}$ é o fluxo extra de água adicionado na cabeceira da parcela, obtido pela diferença entre $q_{i}$ e $q_{c}$ (taxa constante de enxurrada da chuva inicial). Com esses dados, foram estabelecidas as relações lineares entre $D_{p}$ e $q_{m}$ e não lineares entre $\mathrm{C} \mathrm{e} q_{m}$. O comprimento de declive equivalente a cada nível de fluxo $\left(\mathrm{L}_{\mathrm{e}}\right)$ foi computado conforme Cogo (1981), pela equação $\mathrm{L}_{\mathrm{e}}=$ $\left(\mathrm{q}_{\mathrm{a}} / \mathrm{q}_{\mathrm{c}}\right)(\mathrm{L})+\mathrm{L}$, em que L é o comprimento da parcela $(11 \mathrm{~m})$. O comprimento crítico de declive $\left(\mathrm{L}_{\mathrm{c}}\right)$ foi definido no $\mathrm{L}_{\mathrm{e}}$ imediatamente anterior ao nível de fluxo onde ocorreu a falha do resíduo.

\section{RESULTADOS E DISCUSSÃO}

\section{Taxa constante de enxurrada $\left(q_{c}\right)$ da chuva simulada sem os fluxos extras de água}

Os valores de $\mathrm{q}_{\mathrm{c}}$ sobre os resíduos de milho e soja foram, em geral, 19 e $12 \%$ superiores aos obtidos sobre o resíduo de trigo, respectivamente (Quadro 2), sendo esse comportamento atribuído ao tipo de implemento utilizado. Amaral (2010), comparando semeadoras com discos e com discos + hastes, constatou maior infiltração de água no solo no tratamento com discos + hastes. Além disso, o maior número de linhas de plantas de trigo em comparação ao milho e à soja contribuiu para a maior infiltração de água no solo. No geral, os valores de $q_{c}$ variaram pouco entre os tratamentos. Esse comportamento está de acordo com
Kohnke (1968), demonstrando que, a partir do momento em que a capacidade de infiltração de água no solo tornou-se limitada pelo aumento da umidade no solo em função da chuva, as diferenças de escoamento entre os tratamentos foram reduzidas. Infere-se, com isso, que a $\mathrm{q}_{\mathrm{c}}$ ao final da chuva de 90 min (precipitação pluvial total de $97,5 \mathrm{~mm}$ ) era semelhante a uma condição de solo saturado por água - indispensável para viabilizar o cálculo do comprimento crítico de declive.

\section{Relação taxa de erosão $\left(D_{p}\right) \times$ taxa de descarga $\left(\mathbf{q}_{\mathbf{m}}\right)$}

Com base na teoria de Foster et al. (1982a), foram realizadas regressões lineares $(y=a+b x)$ entre $D_{p} e$ $\mathrm{q}_{\mathrm{m}}$, de onde foram obtidos dois coeficientes angulares, o primeiro com os dados anteriores (coeficiente $b_{1}$ ) e o segundo com os dados posteriores (coeficiente $b_{2}$ ) ao ponto de falha, com exceção dos tratamentos onde a falha foi constatada no primeiro nível de fluxo. $A D_{p}$ aqui referida trata apenas da perda de solo ocorrida no último segmento do declive simulado, correspondente ao comprimento da parcela $(11 \mathrm{~m})$.

No teste de chuva sobre o resíduo do milho, houve aumento na $D_{p}$ com o aumento de $q_{m}$ para todos os tratamentos, conforme observado pelos coeficientes angulares positivos (Figuras 1a, b). O mesmo comportamento foi relatado por Foster et al. (1982a), Cogo et al. (1996), Bertol et al. (1997) e Morais \& Cogo (2001). Isso é atribuído ao aumento no volume e na velocidade de enxurrada, refletindo em aumento da energia cisalhante desta. Na menor dose de resíduo, tanto no contorno quanto na pendente, $\mathrm{D}_{\mathrm{p}}$ foi maior quando comparada com a maior dose (dentro do mesmo nível de fluxo), demonstrando a capacidade do resíduo em dissipar a energia cinética das gotas de chuva e, em parte, da enxurrada, funcionando como uma barreira física ao transporte de sedimentos, conforme Wishmeier \& Smith (1978). Foi constatada, em todos os tratamentos, mudança na declividade da reta que relaciona as variáveis $D_{p}$ e $q_{m}$, a partir dos pontos indicados pelas setas na figura. A mudança de declividade da reta ocorreu entre os níveis 5 e $6 ; 4$ e 5 ; 4 e 5; e 3 e 4, nos tratamentos $\mathrm{CM}_{1 / 1}, \mathrm{CM}_{1 / 2}, \mathrm{PM}_{1 / 1}$ e $\mathrm{PM}_{1 / 2}$, respectivamente. Com isso, identificou-se a falha do resíduo de milho, demonstrando que, a partir de determinada $q_{m}$ que representa a enxurrada proveniente de declives mais longos, houve redução da eficácia do resíduo no controle da erosão hídrica, independentemente da quantidade do resíduo e da direção de semeadura, comprovando a teoria da falha de Foster et al. (1982a). Antes da falha, na presença do resíduo na superfície, a tensão cisalhante da enxurrada era distribuída - parte atuando no solo e parte atuando no resíduo. Com a remoção do resíduo, a enxurrada atuou diretamente sobre o solo, mais concentrada em sulcos, o que aumentou a $\mathrm{D}_{\mathrm{p}}$. Após a falha, os coeficientes angulares e os valores de $D_{p}$ foram maiores nos tratamentos que receberam a metade da dose do resíduo de milho. Assim, na maior 
dose, houve menor perda de eficácia do resíduo no controle da erosão hídrica.

No teste de chuva sobre o resíduo de trigo, nos tratamentos em contorno $\left(\mathrm{CT}_{1 / 1} \mathrm{e} \mathrm{CT}_{1 / 2}\right)$, a linearidade entre as variáveis foi observada (Figura 1c). No entanto, os valores de $\mathrm{D}_{\mathrm{p}}$ diminuíram com o aumento da $\mathrm{q}_{\mathrm{m}}$ até o quarto nível de fluxo extra, independentemente da dose do resíduo de trigo. Esse comportamento pode estar relacionado à utilização das hastes sulcadoras durante a semeadura e ao tipo de cultura utilizada. $\mathrm{O}$ aumento da rugosidade orientada pelo preparo, resultante do efeito das hastes, conforme constatado por Amaral (2010), e o grande número de colmos de trigo dispostos em contorno apresentaram forte efeito no controle da velocidade de enxurrada e funcionaram como eficiente barreira ao transporte de sedimentos, corroborando os resultados de Luciano et al. (2009) e Barbosa et al. (2010). Com isso, nos primeiros níveis de fluxo, com menor $\mathrm{q}_{\mathrm{m}}$, os sedimentos mais finos e prontamente disponíveis (devido à mobilização de solo na linha de semeadura) foram removidos pela enxurrada. Com o aumento da $\mathrm{q}_{\mathrm{m}}$ diminuíram os sedimentos finos, e os mais grosseiros ficaram retidos. Nesses tratamentos, houve mudança no coeficiente angular da relação linear entre as variáveis $D_{p}$ e $q_{m}$, no intervalo entre os níveis 4 e 5 (Figura 1c). A partir desse intervalo, o coeficiente angular da reta passou a ser positivo, indicando aumento da $D_{p}$ com o aumento de $q_{m}$, pelo aumento do grau de sulcamento do solo. Com isso, identificou- se o ponto em que ocorreu a falha do resíduo de trigo. Quanto aos tratamentos na pendente (Figura 1d), a falha ocorreu nos primeiros níveis de fluxo. No $\mathrm{PT}_{1 / 1}$, os coeficientes angulares da relação $D_{p}$ e $q_{m}$ foram positivos antes e após o ponto de falha; a mudança na declividade da reta ocorreu entre os níveis 2 e 3 . No $\mathrm{PT}_{1 / 2}$, a falha ocorreu entre os níveis 1 e 2 ; em razão disso, não foi possível obter o coeficiente angular antes da falha para este tratamento. Os coeficientes angulares obtidos após a falha do resíduo de trigo foram pequenos nos tratamentos em contorno quando comparados aos observados na direção da pendente, $\mathrm{e}$ os valores de $D_{p}$ foram inferiores na maior dose em relação à menor, tanto antes quanto após a falha. Chama a atenção o fato de que os valores de $D_{p}$ nos tratamentos executados na direção da pendente para o resíduo de trigo foram superiores aos observados para o resíduo de milho (Figuras $1 b$, d). Isso ocorreu devido à maior mobilização de solo pelas hastes sulcadoras durante a operação de semeadura sobre o resíduo de trigo, deixando o solo mais suscetível ao transporte em direção à pendente pela linha de semeadura, em comparação com a utilização apenas de discos de corte na semeadura sobre o resíduo de milho, os quais mobilizaram menos o solo. $\mathrm{O}$ fato de as hastes mobilizarem o solo com maior intensidade em comparação com o uso isolado dos discos de corte também foi constatado por Camara \& Klein (2005) e Amaral (2010). Com base nisso, infere-se que o uso de hastes sulcadoras no sentido da pendente pode

Quadro 2. Taxa constante de enxurrada da chuva inicial $\left(q_{c}\right)$, nível de fluxo extra no comprimento crítico, taxa de descarga no comprimento crítico $\left(q_{m}\right)$ e comprimento crítico de declive $\left(L_{c}\right)$ para chuva de $65 \mathrm{~mm} \mathrm{~h}^{-1}$ nos diferentes tratamentos

\begin{tabular}{|c|c|c|c|c|}
\hline Tratamento & $\mathbf{q}_{\mathbf{c}}$ & Nível de fluxo extra & $\mathbf{q}_{\mathbf{m}}$ & $\mathbf{L}_{\mathbf{c}}$ \\
\hline & $\mathrm{mm} \mathrm{h}^{-1}$ & & $\mathrm{~m}^{3} \mathrm{~s}^{-1} \mathrm{~m}^{-1} \times 10^{-3}$ & $\mathrm{~m}$ \\
\hline $\mathrm{CM}_{1 / 1}$ & $39 \pm 2,3$ & $5^{\circ}$ & $1,63 \pm 0,07$ & $155 \pm 15$ \\
\hline $\mathrm{CM}_{1 / 2}$ & $34 \pm 0,3$ & $4^{\circ}$ & $1,15 \pm 0,08$ & $126 \pm 09$ \\
\hline $\mathrm{PM}_{1 / 1}$ & $42 \pm 2,8$ & $4^{\circ}$ & $1,37 \pm 0,05$ & $124 \pm 03$ \\
\hline $\mathrm{PM}_{1 / 2}$ & $35 \pm 2,0$ & $3^{\circ}$ & $1,00 \pm 0,10$ & $109 \pm 05$ \\
\hline $\mathrm{CT}_{1 / 1}$ & $28 \pm 7,2$ & $4^{\circ}$ & $1,10 \pm 0,05$ & $147 \pm 30$ \\
\hline $\mathrm{CT}_{1 / 2}$ & $32 \pm 6,6$ & $4^{o}$ & $1,15 \pm 0,13$ & $135 \pm 39$ \\
\hline $\mathrm{PT}_{1 / 1}$ & $32 \pm 1,3$ & $2^{\circ}$ & $0,69 \pm 0,17$ & $82 \pm 17$ \\
\hline $\mathrm{PT}_{1 / 2}$ & $34 \pm 0,3$ & $1^{\circ}$ & $0,36 \pm 0,03$ & $44 \pm 04$ \\
\hline $\mathrm{CS}_{1 / 1}$ & $35 \pm 2,5$ & $4^{\circ}$ & $1,29 \pm 0,04$ & $137 \pm 16$ \\
\hline $\mathrm{CS}_{1 / 2}$ & $36 \pm 2,1$ & $2^{\circ}$ & $0,60 \pm 0,02$ & $66 \pm 03$ \\
\hline $\mathrm{PS}_{1 / 1}$ & $35 \pm 2,8$ & $2^{\circ}$ & $0,69 \pm 0,18$ & $76 \pm 24$ \\
\hline $\mathrm{PS}_{1 / 2}$ & $35 \pm 2,7$ & $1^{\circ}$ & $0,29 \pm 0,05$ & $35 \pm 02$ \\
\hline
\end{tabular}

C: semeadura em contorno ao declive; P: semeadura no sentido da pendente; M:resíduo de milho; T: resíduo de trigo; S: resíduo de soja; ${ }_{1 / 1}$-dose de resíduo de $100 \%$ do total produzido; ${ }_{1 / 2}$-dose de resíduo de $50 \%$ do total produzido. (Média das repetições \pm desvio-padrão) 

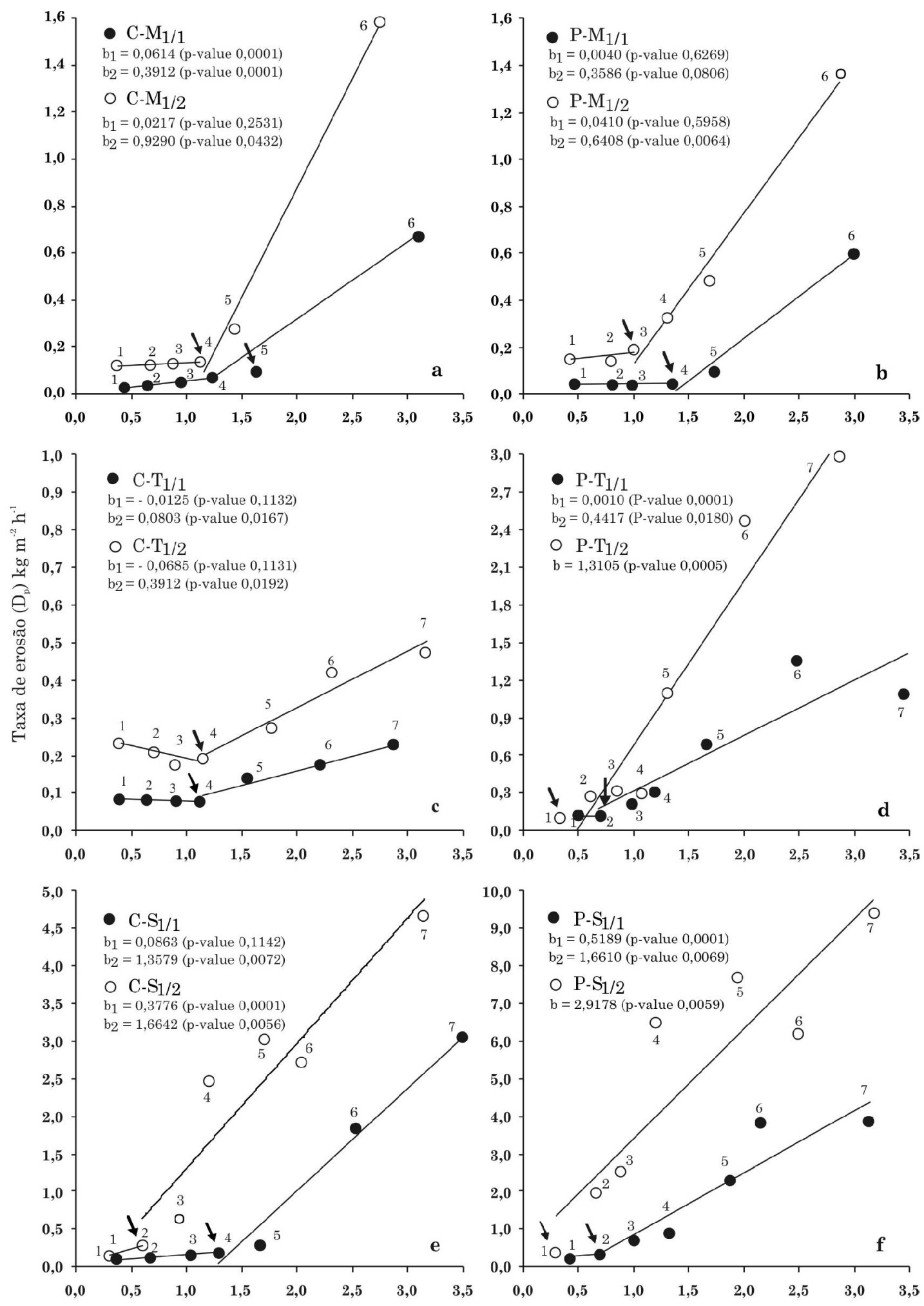

Taxa de descarga $\left(\mathrm{q}_{\mathrm{m}}\right), \mathrm{m}^{3} \mathrm{~s}^{-1} \mathrm{~m}^{-1} \times 10^{-3}$

Figura 1. Relação entre a taxa de erosão $\left(D_{p}\right)$ e a taxa de enxurrada no ponto médio da parcela experimental $\left(q_{m}\right)$, nos diferentes tratamentos estudados. $C$-semeadura em contorno ao declive; $P$-semeadura no sentido da pendente; M: resíduo de milho; T: resíduo de trigo; S: resíduo de soja; 1/1 $_{\mathbf{1}}$-dose de resíduo de $100 \%$ do total produzido; ${ }_{1 / 2}$-dose de resíduo de $50 \%$ do total produzido. Obs.: o número sobre cada ponto na figura indica o nível de fluxo extra adicionado, e as setas indicam o ponto onde houve mudança na relação $\mathbf{D}_{\mathbf{p}} \times \mathbf{q}_{\mathrm{m}}$. 
proporcionar elevada taxa de erosão em maiores taxas de enxurrada. No geral, identificou-se a falha do resíduo de trigo em todos os tratamentos, independentemente da direção de semeadura e da dose do resíduo.

No teste de chuva sobre o resíduo da soja, nos tratamentos $\mathrm{CS}_{1 / 1}, \mathrm{CS}_{1 / 2}$ e $\mathrm{PS}_{1 / 1}$, constatou-se mudança na declividade da reta que relaciona as variáveis $D_{p}$ e $q_{m}$ entre os níveis 4 e 5; 2 e 3; e 2 e 3, respectivamente (Figuras 1e, f). No $\mathrm{PS}_{1 / 2}$, não foi possível obter o coeficiente angular da relação com os dados anteriores à falha, pelo fato de ela ter ocorrido entre os níveis 1 e 2(Figura 1f). Após o ponto de falha, os coeficientes angulares foram altos em todos os tratamentos, sendo maiores na metade da dose, independentemente da direção de semeadura, e maiores na semeadura na pendente, independentemente da dose do resíduo. Os valores elevados desse coeficiente indicam grande redução de eficácia do resíduo de soja após a falha, aumentando a $\mathrm{D}_{\mathrm{p}}$. Após a falha, ocorreu grande dispersão entre os pontos da relação $D_{p} \times q_{m}$, possivelmente ocasionada pelo fato de o resíduo ora estar amontoado/ancorado, ora deslocado pelo maior fluxo, respectivamente, ora aprisionando e ora liberando parte dos sedimentos em suspensão no fluxo, conforme destacam Foster et al. (1982a). No campo, durante a execução do teste, foi observado que o resíduo de soja, por ser leve e pela baixa rugosidade do solo, foi facilmente deslocado pela enxurrada, deixando o solo com baixa cobertura após a falha. A combinação de baixa cobertura do solo, baixa densidade de hastes das plantas de soja (pouco eficientes na filtragem de sedimentos) e pequena rugosidade criada pelos discos da semeadora potencializou a erosão, o que proporcionou valores de $\mathrm{D}_{\mathrm{p}}$ superiores aos observados sobre os resíduos de milho e trigo, independentemente da dose de resíduo e da direção de semeadura (Figura 1).

\section{Relação concentração de sedimentos na enxurrada (C) $x$ taxa de descarga $\left(q_{m}\right)$}

Da relação entre $\mathrm{C}$ e $\mathrm{q}_{\mathrm{m}}$, o aumento na $\mathrm{C}$ foi utilizado para identificar o ponto de falha. Foram ajustadas equações do tipo inversa de primeira ordem $(\mathrm{y}=\mathrm{a}+(\mathrm{b} / \mathrm{x}))$, de onde foram obtidos dois coeficientes $\left(b_{1}\right.$ e $\left.b_{2}\right)$, o primeiro com os dados anteriores e o segundo com os dados posteriores ao ponto de falha, com exceção dos tratamentos em que a falha ocorreu no primeiro nível de fluxo.

Sobre o resíduo de milho, a $\mathrm{C}$ diminuiu com o aumento da $\mathrm{q}_{\mathrm{m}}$, até o ponto de falha (Figura 2a, b), concordando com dados obtidos por Bertol (1995) e Morais (1999). Esse comportamento foi menos aparente no tratamento $\mathrm{CM}_{1 / 1}$. A redução da carga de sedimentos prontamente disponíveis ao transporte e o efeito de diluição dos sedimentos nas maiores taxas de descarga explicam a redução da C. Nos mesmos intervalos onde houve mudança na inclinação da reta da relação $D_{p} x$ $\mathrm{q}_{\mathrm{m}}$, a $\mathrm{C}$ aumentou de forma nítida, indicando a falha do resíduo cultural de milho. Com isso, a remoção do resíduo pela energia cisalhante do fluxo concentrado aumentou a taxa de erosão em sulcos e a produção de sedimentos, de acordo com a teoria de Foster et al. (1982a). Destaca-se, ainda, a grande diferença na C entre as doses do resíduo, demonstrando que a cobertura do solo é o principal fator que diminui a erosão. Isso decorre do efeito do resíduo em reduzir a desagregação do solo e o transporte de sedimentos, além de aumentar a deposição dos sedimentos dentro da própria área.

Quanto ao resíduo de trigo, a falha foi identificada na pendente (Figura 2d). No $\mathrm{PT}_{1 / 2}$, ela ocorreu entre os níveis $1 \mathrm{e} 2$, onde a $\mathrm{C}$ aumentou de 0,70 para $0,93 \mathrm{~g} \mathrm{~L}^{-1}$. No $\mathrm{PT}_{1 / 1}$, ela ocorreu entre os níveis 2 e 3 , onde a $\mathrm{C}$ aumentou de 0,44 para $0,65 \mathrm{~g} \mathrm{~L}^{-1}$. Após a falha, com 0 aumento da taxa de descarga nos maiores níveis de fluxo extra, a $\mathrm{C}$ aumentou substancialmente, atingindo picos de 1,60 e $3,75 \mathrm{~g} \mathrm{~L}^{-1}$ no $\mathrm{PT}_{1 / 1}$ e $\mathrm{PT}_{1 / 2}$, respectivamente. A relação $\mathrm{C} \times \mathrm{q}_{\mathrm{m}}$ não detectou a falha do resíduo de trigo no contorno $\left(\mathrm{CT}_{1 / 1}\right.$ e $\left.\mathrm{CT}_{1 / 2}\right)$, onde a $\mathrm{C}$ diminuiu drasticamente nos primeiros níveis de fluxo e estabilizou-se nas maiores taxas de descarga em valores próximos de 0,3 e $0,5 \mathrm{~g} \mathrm{~L}^{-1}$ no $\mathrm{CT}_{1 / 1}$ e $\mathrm{CT}_{1 / 2}$, respectivamente (Figura 2c). Com isso, a relação $D_{p} x$ $\mathrm{q}_{\mathrm{m}}$ foi a que teve sensibilidade em detectar a falha do resíduo (aumento da contribuição dos sulcos para a erosão hídrica) nesses tratamentos. De modo geral, a $\mathrm{C}$ foi maior na metade da dose de resíduo, em comparação com a maior dose.

No tocante ao resíduo de soja (Figuras 2e, f), no tratamento $\mathrm{PS}_{1 / 2}$, a $\mathrm{C}$ aumentou $113 \%$ entre os níveis de fluxo 1 e 2 . Com isso, foi constatada a falha do resíduo no primeiro intervalo. Nos tratamentos $\mathrm{CS}_{1 / 2}$ e $\mathrm{PS}_{1 / 1}$, a $\mathrm{C}$ teve leve diminuição entre os níveis 1 e 2 , aumentando $50 \%$ (em ambos os tratamentos) no intervalo entre os níveis 2 e 3 . No $\mathrm{CS}_{1 / 1}$, a $\mathrm{C}$ diminuiu do primeiro ao quarto nível de fluxo, aumentando $59 \%$ no quinto nível. Em todos os tratamentos, foi possível definir o intervalo de falha, o qual foi condizente com $o$ verificado pela relação $D_{p} \times q_{m}$. Com a falha do resíduo de soja, a $\mathrm{C}$ aumentou inversamente com o incremento da dose e em função da direção de semeadura (maior na pendente). Foram observados picos de 2,$7 ; 5,9 ; 5,1 ;$ e $20,3 \mathrm{~g} \mathrm{~L}^{-1}$, no $\mathrm{CS}_{1 / 1}, \mathrm{CS}_{1 / 2}$, $\mathrm{PS}_{1 / 1}$ e $\mathrm{PS}_{1 / 2}$, respectivamente.

\section{Comprimento crítico de declive $\left(L_{c}\right)$}

O comprimento crítico de declive $\left(L_{c}\right)$ foi considerado o comprimento equivalente de declive simulado $\left(\mathrm{L}_{\mathrm{e}}\right)$ do nível de fluxo anterior à ocorrência da falha dos resíduos. Adotou-se esse critério por ser mais conservacionista, já que a falha poderia ter ocorrido em qualquer taxa de descarga entre o nível de fluxo extra de ocorrência da falha e o nível de fluxo anterior a ela. Portanto, o $\mathrm{L}_{\mathrm{c}}$ estabelecido é uma aproximação do comprimento crítico real, podendo ser igual ou menor. A escolha de um nível de fluxo imediatamente antes da falha (nível de fluxo crítico) permite a certeza de que a tensão cisalhante do fluxo nesse ponto não era superior à resistência 

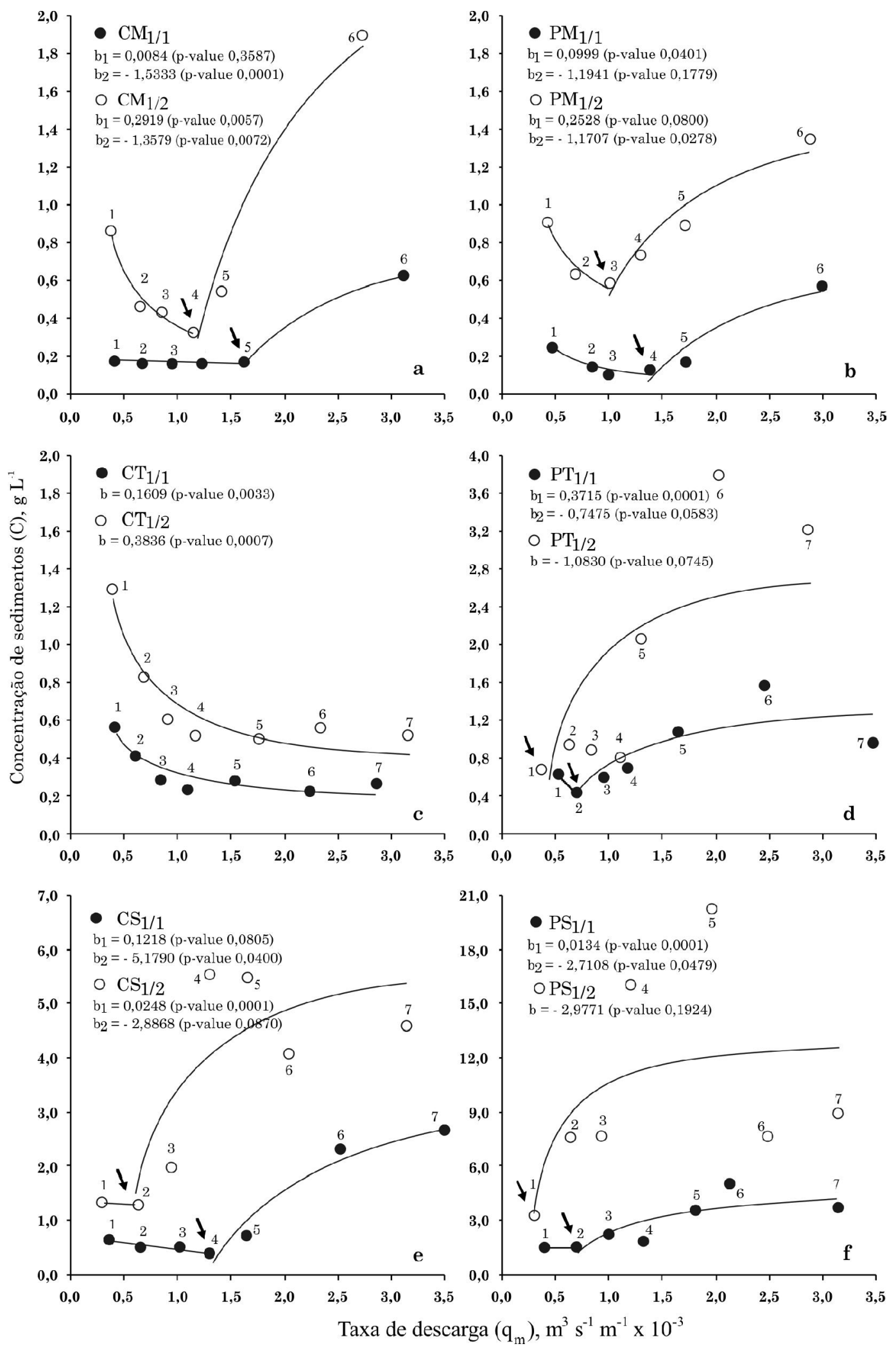

Figura 2. Relação entre a concentração de sedimentos na enxurrada (C) e a taxa de enxurrada no ponto médio da parcela experimental $\left(q_{m}\right)$, nos diferentes tratamentos estudados. C: semeadura em contorno ao declive; P: semeadura no sentido da pendente; M: resíduo de milho; T: resíduo de trigo; S: resíduo de soja; ${ }_{1 / 1}$-dose de resíduo de $100 \%$ do total produzido; ${ }_{1 / 2}$-dose de resíduo de $50 \%$ do total produzido. Obs.: o número sobre cada ponto na figura indica o nível de fluxo extra adicionado, e as setas indicam o ponto onde houve mudança na relação $\mathrm{C} \times \mathbf{q}_{\mathrm{m}}$. 
imposta pelo resíduo e, ou, pelo solo. Na figura 3 são mostrados os comprimentos equivalentes de declive $\left(L_{e}\right)$ para cada nível de fluxo extra adicionado, nos diferentes tratamentos sobre os resíduos de milho, trigo e soja.

Conforme identificada a falha dos resíduos, o comprimento crítico de declive $\left(\mathrm{L}_{\mathrm{c}}\right)$ ocorreu para todos os tratamentos (Quadro 2). Sobre o resíduo de milho, ele variou de 109 a $155 \mathrm{~m}$; no de trigo, de 44 a $147 \mathrm{~m}$; e no de soja, de 35 a $137 \mathrm{~m}$. De maneira geral, a semeadura em contorno e a maior dose de resíduos aumentaram o Lc em relação à pendente $\mathrm{e}$ à menor dose. Na média, os aumentos foram de 21 , 124 e $83 \%$ no contorno em relação à pendente e de 19,28 e $111 \%$ na maior dose em relação à menor, nos resíduos de milho, trigo e soja, respectivamente. Com isso, ressalta-se a importância das maiores quantidades de resíduos para aumentar o comprimento crítico de declive. Também, isso comprova que a prática conservacionista complementar "cultivo em contorno" dificulta a remoção dos resíduos pelo fluxo superficial, aumentando o comprimento crítico de declive.

Para condições semelhantes ao experimento (grau de compactação e tipo de solo, intensidade de precipitação e declividade), os comprimentos críticos podem ser uma referência para auxiliar na definição

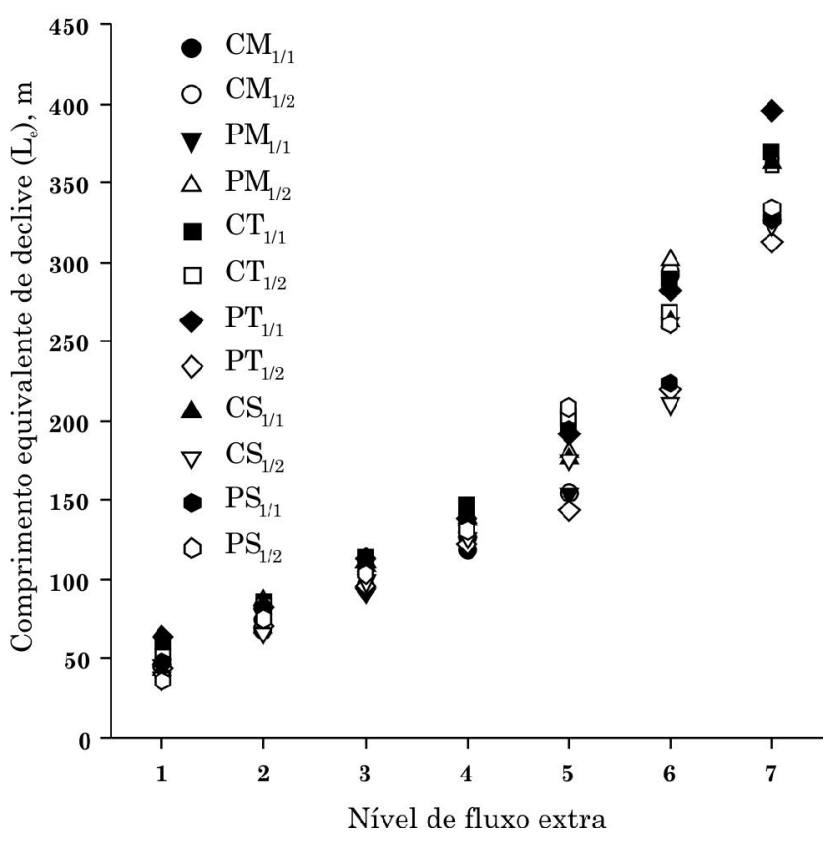

Figura 3. Comprimento equivalente de declive simulado e correspondente nível de fluxo extra, nos diferentes tratamentos. C: semeadura em contorno ao declive; $P$ : semeadura no sentido da pendente; M: resíduo de milho; $T$ : resíduo de trigo; S: resíduo de soja; $1 / 1$-dose de resíduo de $100 \%$ do total produzido; $1 / 2$-dose de resíduo de $\mathbf{5 0} \%$ do total produzido. da distância entre terraços agrícolas, pois, a partir desse ponto no terreno, os resíduos culturais teriam sua eficiência reduzida no controle da erosão hídrica. Bertol et al. (2000) afirmam que é importante deixar claro que o ponto no terreno onde ocorre a perda da eficácia relativa dos resíduos no controle da erosão hídrica não contempla a tolerância de perda de solo nem a capacidade de armazenamento ou de drenagem de água dos canais de terraços, os quais poderão estabelecer comprimentos de rampa maiores ou menores que o comprimento crítico.

\section{Remoção dos resíduos culturais e condição final da superfície do solo pela adição dos fluxos extras de água}

Por meio de observação em campo durante a chuva, fez-se uma descrição da forma de remoção dos resíduos culturais e da condição final da superfície do solo nos tratamentos estudados, em função da adição dos fluxos extras de água.

A remoção de resíduo de milho foi observada em campo. Nos tratamentos em que a semeadura foi realizada na direção da pendente, o resíduo foi deslocado principalmente nas entrelinhas das soqueiras do milho, conforme também constatado por Morais (1999), ao passo que, na semeadura em contorno, ele ocorreu nos locais onde o rodado do trator destruiu as soqueiras de plantas de milho durante a operação de semeadura. O resíduo que ancorou nas soqueiras não foi alterado pelo rodado do trator e, por isso, reteve parte dos sedimentos transportados pela enxurrada. De modo geral, não houve a formação de sulcos aparentes (Figuras 4a, b, c, d), pois a mobilização do solo ocasionada pelos discos da semeadora foi pequena, insuficiente para tornar a superfície do solo suscetível ao sulcamento. Nos locais onde o resíduo falhou, o solo ficou exposto.

A remoção de resíduo de trigo foi pouco aparente. $\mathrm{Na}$ semeadura realizada em direção à pendente, o escoamento concentrou-se nas linhas de atuação das hastes da semeadora e, aos poucos, pela adição de níveis mais altos de fluxo, sedimentos de solo e peças de resíduo da área dos sulcos de semeadura foram removidos. Na semeadura realizada em contorno, o grande número de colmos de trigo e a rugosidade orientada criada pela operação de semeadura formaram pequenos patamares na superfície do terreno, influenciando a lâmina de escoamento de uma linha de semeadura para outra, permitindo passagem do fluxo de um patamar a outro por entre os colmos. Nos maiores fluxos, o escoamento concentrou-se em locais onde houve rompimento de pequenos diques formados pelos sulcos de semeadura e pelos resíduos amontoados. Ao final, nos tratamentos de semeadura na pendente, a maior parte do solo mobilizado pelas hastes e o resíduo foram removidos das parcelas nas áreas dos sulcos formados pela semeadura, enquanto nos tratamentos em contorno eles foram pouco removidos das parcelas (Figuras 4e, f, g, h). 

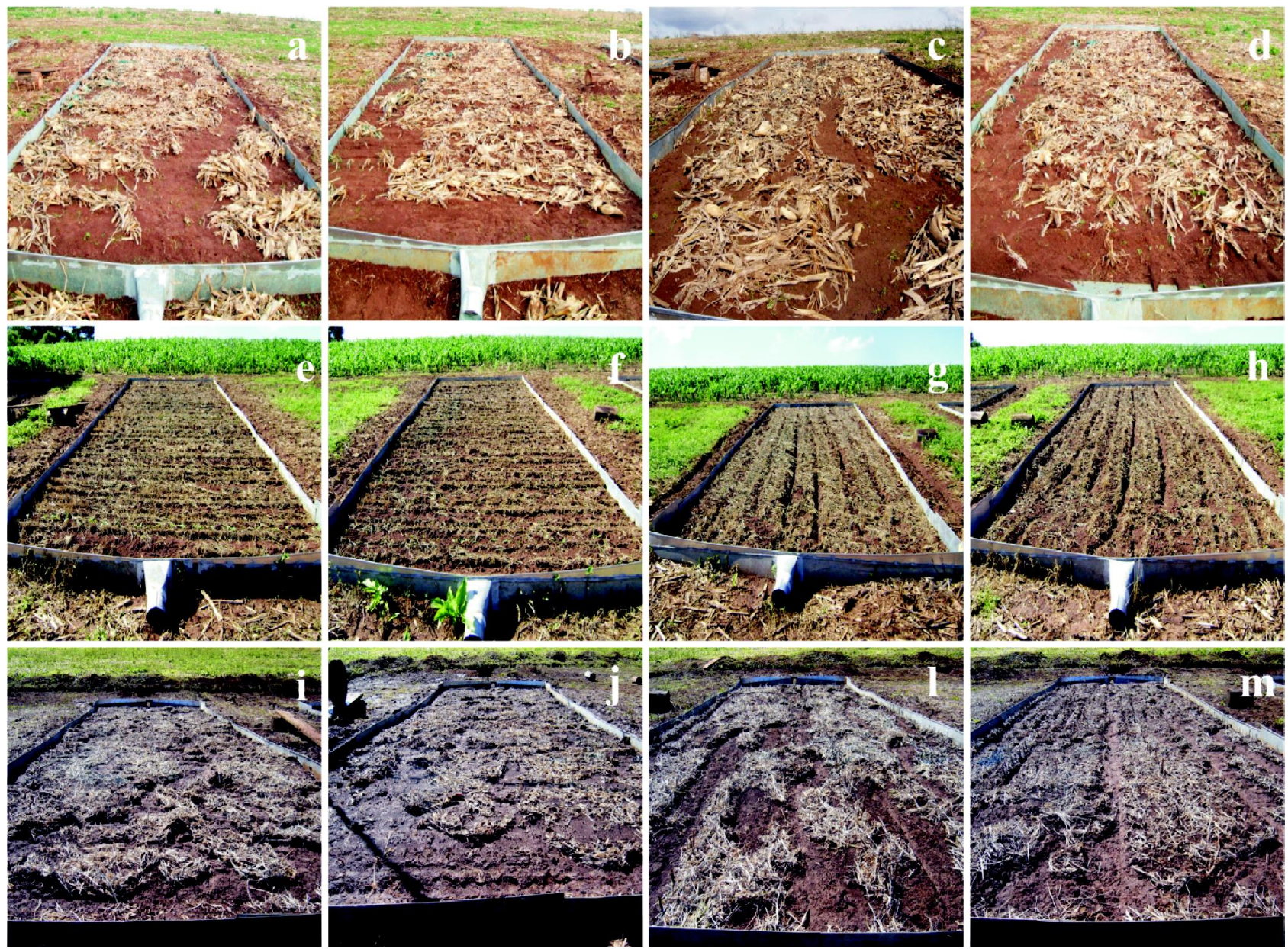

Figura 4. Vista da superfície do solo nos diferentes tratamentos após a falha do resíduo cultural, no teste de

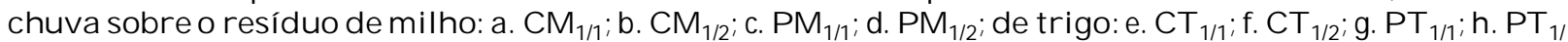
${ }_{2}$; e de soja: i. $\mathrm{CS}_{1 / 1} ;$ j. $\mathrm{CS}_{1 / 2} ; 1 . \mathrm{PS}_{1 / 1} ; \mathrm{m} . \mathrm{PS}_{1 / 2}$.

A remoção do resíduo de soja foi possível de ser observada. Esse resíduo, por ser leve e mais volumoso do que o de trigo, facilitou a identificação visual, apesar de ambos terem produzido a mesma quantidade. Nos tratamentos realizados em direção à pendente, o escoamento concentrou-se nas linhas onde atuaram os discos da semeadora, ao passo que naqueles em contorno o escoamento concentrou-se entre as soqueiras dos colmos de soja. Ao final, nos tratamentos na pendente, formaram-se sulcos nos locais onde atuaram os discos da semeadora, enquanto naqueles em contorno houve a formação de sulcos pelos locais onde ocorreu a remoção do resíduo (Figura 4i, j, l, m). Contudo, observou-se que em todos os tratamentos houve expressiva redução da cobertura do solo por erosão.

\section{CONCLUSÕES}

1. Foi comprovada a ocorrência de falha dos resíduos culturais em semeadura direta, o que caracterizou o comprimento crítico de declive; esse comprimento estabeleceu um ponto no terreno a partir do qual os resíduos tiveram sua eficácia reduzida no controle da erosão hídrica.

2. A direção de semeadura em contorno e a maior dose dos resíduos culturais aumentaram o comprimento crítico de declive em relação à semeadura na direção da pendente e à menor dose dos resíduos, respectivamente.

3. O ponto de falha dos resíduos culturais foi mais bem identificado quando foram analisadas conjuntamente as relações: taxa de erosão $\left(D_{p}\right) x$ taxa de descarga $\left(\mathrm{q}_{\mathrm{m}}\right)$ e concentração de sedimentos na enxurrada $(C) \times$ taxa de descarga $\left(q_{m}\right)$.

4. O tipo de resíduo cultural e a forma de realização da operação de semeadura, diferenciados para cada experimento, influenciaram o comprimento crítico de declive; para os resíduos de milho, trigo e soja, eles variaram de 109 a $155 \mathrm{~m}$, de 44 a $147 \mathrm{~m}$ e de 35 a $137 \mathrm{~m}$, respectivamente. 


\section{LITERATURA CITADA}

AMARAL, A.J. Erosão hídrica e limites críticos de comprimento de declive para seu efetivo controle, em diferentes tipos e doses de resíduo cultural e dois modos de semeadura direta. Porto Alegre, Universidade Federal do Rio Grande do Sul, 2010. 144p. (Tese de Doutorado)

BARBOSA, F.T.; BERTOL, I.; LUCIANO, R.V. \& PAZFERREIRO, J. Proporção e tamanho de sedimentos e teor de carbono orgânico na enxurrada e no solo para dois cultivos e duas formas de semeadura. R. Bras. Ci. Solo, 34:1701-1710, 2010.

BARBOSA, F.T. Comprimento crítico de declive relacionado à erosão hídrica, em diferentes tipos e doses de resíduo em duas direções de semeadura direta. Lages, Universidade do Estado de Santa Catarina, 2011. 99p. (Tese de Doutorado)

BERTOL, I. Comprimento crítico de declive para preparos conservacionistas de solo. Porto Alegre, Universidade Federal do Rio Grande do Sul, 1995. 185p. (Tese de Doutorado)

BERTOL, I. \& COGO, N.P. Terraceamento em sistemas de preparo conservacionista de solo: um novo conceito. Lages, Núcleo Regional Sul da Sociedade Brasileira de Ciência do Solo, 1996. 41p. (Boletim Técnico, 1)

BERTOL, I.; COGO, N.P. \& LEVIEN, R. Comprimento crítico de declive em sistemas de preparos conservacionistas de solo. R. Bras. Ci. Solo, 21:139-148, 1997.

BERTOL, I.; COGO, N.P. \& CASSOL, E.A. Distância entre terraços usando o comprimento crítico de rampa em dois preparos conservacionistas de solo. R. Bras. Ci. Solo, $24: 417-425,2000$.

CAMARA, R.A. \& KLEIN, V.A. Escarificação em plantio direto como técnica de conservação do solo e da água. R. Bras. Ci. Solo, 29:789-796, 2005.

COGO, N.P. Effect of residue cover, tillage-induced roughness and slope lenght on erosion and related parameters. Indiana. West Lafayette, Purdue University, 1981. 346p. (Tese de Doutorado)

COGO, N.; FOSTER, G.R. \& MOLDENHAUER, W.C. Flow rates-soil erosion relationships as affected by wheat residue cover: an attempt to define slope length limits for conservation tillage. R. Bras. Ci. Solo, 20:475-483, 1996.

COGO, N.P.; LEVIEN, R. \& SCHWARZ, R.A. Perdas de solo e água por erosão hídrica influenciadas por métodos de preparo do solo, classes de declive e níveis de fertilidade do solo. R. Bras. Ci. Solo, 27:743-753, 2003.

DENARDIN, J.E.; KOCHHANN, R.A.; FLORES, C.A.; FERREIRA, T.N.; CASSOL, E.A.; MONDARDO, A. \& SCHWARZ, R.A. Manejo de enxurrada em sistema plantio direto. Porto Alegre, Fórum Estadual de Solo e Água, 2005. 88 p.

EMPRESA BRASILEIRA DE PESQUISA AGROPECUÁRIA EMBRAPA. Sistema brasileiro de classificação de solos. 2.ed. Rio de Janeiro, Embrapa Solos, 2006. 306p.
FOSTER, G.R.; JOHNSON, C.B. \& MOLDENHAUER, W.C. Critical slope lenghts for unanchored cornstalk and wheat straw residue. Trans. Am. Soc. Agric. Eng., 25:935-947, 1982a.

FOSTER, G.R.; JOHNSON, C.B. \& MOLDENHAUER, W.C. Hydraulics of failure of unanchored cornstalk and wheat straw mulches for erosion control. Trans. Am. Soc. Agric. Eng., 25:940-947, 1982b.

INSTITUTO AGRONÔMICO DO PARANÁ - IAPAR. Recomendações gerais do encontro sobre uso do simulador de chuva em pesquisa de conservação do solo no Brasil. Im: $1^{\circ}$ Encontro nacional de pesquisa de erosão com simuladores de chuva, 7-11 de junho de 1975, Londrina. Anais... Londrina. 1975. p.107-120.

KOHNKE, H. Soil physics. New York, McGraw-Hill, 1968. 224p.

LAFLEN, J.M.; BACKER, J.L. \& HARTWING, R.O. Soil and water loss from conservation tillage systems. Trans. Am. Soc. Agric. Eng., 39:2139-2145, 1978.

LUCIANO, R.V.; BERTOL, I.; BARBOSA, F.T.; VÁZQUEZ, E.V. \& FABIAN, E.L. Perdas de água e solo por erosão hídrica em duas direções de semeadura de aveia e ervilhaca. R. Bras. Ci. Solo, 33:669-676, 2009.

MORAIS, L.F.B. Comprimentos críticos de declive para diferentes manejos de resíduos culturais no sistema plantio direto em um solo Podzólico da Depressão CentralRS. Porto Alegre, Universidade Federal do Rio Grande do Sul, 1999. 162p. (Tese de Doutorado)

MORAIS, L.F.B. \& COGO, N.P. Comprimentos críticos de rampa para diferentes manejos de resíduos culturais em sistema de semeadura direta em um Argissolo Vermelho na Depressão Central-RS. R. Bras. Ci. Solo, 25:1041-1051, 2001.

RENARD, K.G.; FOSTER, G.R.; WEESIES, G.A.; McCOOL, D.K. \& YODER, D.C. Predicting soil erosion by water: A guide to conservation planning with the Revised Universal Soil Loss Equation (RUSLE). Washington, U.S. Department of Agricultura, 1997. 384p. (Agriculture Handbook, 703)

SCHICK, J.; BERTOL, I.; BATISTELA, O. \& BALBINOT JUNIOR, A.A. Erosão hídrica em Cambissolo Húmico submetido a diferentes sistemas de preparo e cultivo do solo: I. Perdas de solo e água. R. Bras. Ci. Solo, 24:427-436, 2000.

SLONEKER, L.L. \& MOLDENHAUER, W.C. Measuring the amounts of crop residue remaining after tillage. J. Soil Water Conserv., 32:231-236, 1977.

SWANSON, N.P. A rotating-boom rainfall simulator. Trans. Am. Soc. Agric. Eng., 26:1738-1743, 1965.

SWANSON, N.P. \& DEDRICK, A.R. Simulation of increased slope length on small runoff plots. American Society Engineering, 1966. 8p. (Paper, 66-211)

WISCHMEIER, W.H. Conservation tillage to control water erosion. In: NATIONAL CONSERVATION TILLAGE CONFERENCE, Ankeny, 1973. Proceedings... Ankeny, Soil Conservation American Society, 1973. p.133-141.

WISCHMEIER, W.H. \& SMITH, D.D. Predicting rainfall erosion losses: A guide to conservation planning. Washington, USDA, 1978. 58p. (Agricultural Handbook, 537). 